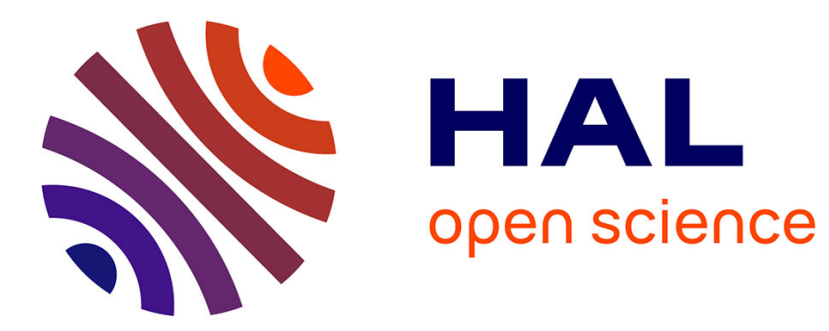

\title{
Consistency of ground-motion predictions from the past four decades
}

\author{
John Douglas
}

\section{To cite this version:}

John Douglas. Consistency of ground-motion predictions from the past four decades. Bulletin of Earthquake Engineering, 2010, 8 (6), pp.1515-1526. 10.1007/s10518-010-9195-5 . hal-00557601

\section{HAL Id: hal-00557601 https://hal-brgm.archives-ouvertes.fr/hal-00557601}

Submitted on 19 Jan 2011

HAL is a multi-disciplinary open access archive for the deposit and dissemination of scientific research documents, whether they are published or not. The documents may come from teaching and research institutions in France or abroad, or from public or private research centers.
L'archive ouverte pluridisciplinaire HAL, est destinée au dépôt et à la diffusion de documents scientifiques de niveau recherche, publiés ou non, émanant des établissements d'enseignement et de recherche français ou étrangers, des laboratoires publics ou privés. 


\title{
Consistency of ground-motion predictions from the past four decades
}

\author{
John Douglas
}

Received: date / Accepted: date

\begin{abstract}
Due to the limited observational datasets available for the derivation of groundmotion prediction equations (GMPEs) there is always epistemic uncertainty in the estimated median ground motion. Because of the increasing quality and quantity of strong-motion datasets it would be expected that the epistemic uncertainty in ground-motion prediction (related to lack of knowledge and data) is decreasing. In this study the predicted median ground motions from over 200 GMPEs for various scenarios are plotted against date of publication to examine whether the scatter in the predictions (a measure of epistemic uncertainty) is decreasing with time.

It is found that there are still considerable differences in predicted ground motions from the various GMPEs and that the variation between estimates is not reducing although the ground motion estimated by averaging median predictions is roughly constant. For western North America predictions for moderate earthquakes have show a high level of consistency since the 1980s as do, but to a lesser extent, predictions for moderate earthquakes in Europe, the Mediterranean and the Middle East. A good match is observed between the predictions from GMPEs and the median ground motions based on observations from similar scenarios. Variations in median ground motion predictions for stable continental regions and subduction zones from different GMPEs are large, even for moderate earthquakes. The large scatter in predictions of the median ground motion shows that epistemic uncertainty in ground-
\end{abstract}

Earthquake Engineering Research Centre, University of Iceland, Austurvegur 2A, 800 Selfoss, Iceland. On teaching leave from: BRGM, Orléans, France. 
motion prediction is still large and that it is vital that this is accounted for in seismic hazard assessments.

Keywords strong-motion data $\cdot$ ground-motion prediction equations (GMPEs) - epistemic uncertainty $\cdot$ shallow crustal earthquakes $\cdot$ stable continental regions (SCRs) · subduction zones

\section{Introduction}

Ground-motion prediction equations (GMPEs) have been developed since the $1960 \mathrm{~s}^{1}$ and to date over 250 models for peak ground acceleration (PGA) and over 150 models for linear elastic response spectral ordinates have been published (Douglas, 2008). During this same period the quality and quantity of strong-motion data available to constrain these models have increased dramatically, particularly in the past two decades with the occurrence of various moderate and large earthquakes in well-instrumented areas (e.g. Loma Prieta, 1989; Northridge, 1994; Kocaeli, 1999; Düzce, 1999; Chi-Chi, 1999; Parkfield, 2004). These data have significantly improved the understanding of strong ground motion. Epistemic uncertainty in ground-motion prediction is related to a lack of data and knowledge and can be large. Within probabilistic seismic hazard assessments it has become standard practice to account for epistemic uncertainty by using logic trees, modeling the degrees of belief in various inputs (e.g. Bommer and Scherbaum, 2008). This uncertainty can have a large impact on the mean probabilities of exceedence. Thanks to the collection and analysis of considerable data from recent earthquakes the epistemic uncertainty in ground-motion prediction should have been coming down since the 1960s. This article investigates whether this is true using a simple technique. It should be noted that the procedures tested here probably only lead to lower bound estimates of epistemic uncertainty — true assessments would require more sophisticated methods and expert judgment. This article extends the analysis of Douglas (2010) to other geographical regions and also it quantifies the scatter in predictions of the median ground motions.

Douglas (2007), Douglas (2010) and Appendix G of Chiou and Youngs (2008) present another technique to assess epistemic uncertainty of ground-motion predictions: calculation of the widths of confidence limits based on uncertainties in regression coefficients. As noted

\footnotetext{
1 Gutenberg and Richter (1956) present some empirical ground-motion estimates but these are not true GMPEs.
} 
by Chiou and Youngs (2008) the computation of confidence limits for non-linear functional forms and non-standard regression techniques (e.g. maximum-likelihood) is not straightforward and requires the development of new techniques. Therefore, in this brief article such an approach has not been attempted.

In the next section, median predicted ground motions from hundreds of GMPEs are plotted against publication date to see whether these predictions are tending to a single value, which in the absence of epistemic uncertainty they should. In addition, because it is important to check consistency between predictions and observations, to these graphs are added the median ground motion (and its confidence limits) for the considered scenarios based on strong-motion records from a large databank. Strasser et al (2009), following Douglas (2003), show that aleatory variabilities associated with empirical GMPEs do not show much variation with time and are generally between 0.25 and 0.35 in terms of common (base 10) logarithms. Therefore, this aspect of consistency is not reconsidered here.

\section{Comparing ground-motion predictions}

The empirical ground-motion models up to the end of 2008 summarized in the reports of Douglas $(2004,2006,2008)$ have been programmed. Some authors do not report the coefficients of their models or the original reference of the model could not be retrieved and, therefore, a few of the listed GMPEs were not coded. In total 254 empirical GMPEs are considered here. In addition, 26 models (generally for stable continental regions, SCRs) based on ground-motion simulations, often the stochastic method but sometimes the hybrid empirical-stochastic method (Campbell, 2003) or the referenced-empirical approach (Atkinson, 2008), were also included in this analysis (some of these models provide multiple sets of coefficients to account for epistemic uncertainty, which have been considered in the analysis for SCRs). When sufficient information exists the differences in independent variables (e.g. magnitudes, style-of-faulting, horizontal component definition and source-to-site distance) between models have been minimized using the methods and equations discussed in Bommer et al (2005) and Beyer and Bommer (2006). Many (particularly early) studies do not provide sufficient information on, for example, magnitude scales used or definition of horizontal component so these adjustments could not be made. Therefore, the predictions shown for some models could be in error by up to $20 \%$ but this should not affect the overall behaviour. 
For this article, models have been adjusted to: moment magnitude $\left(M_{w}\right)$, distance to the surface projection of the rupture (Joyner-Boore distance) $\left(r_{j b}\right)$, vertical-dipping strikeslip faulting and the geometric mean of the two horizontal components. The size of the rupture plane and other additional parameters needed to evaluate some of the models have been computed using the methods given in Chapter 7 of Campbell and Bozorgnia (2007). To compute the epicentral and hypocentral distances the hypocentre has been assumed to be at one end of the fault at a depth of $10 \mathrm{~km}$ and the site half way along the fault. Only two strong-motion intensity parameters are considered here: PGA and (pseudo)-spectral acceleration (SA) at $1 \mathrm{~s}$ natural period and 5\% damping. Some datasets (e.g. Joyner and Boore, 1981) have become standards for the testing of new regression techniques; this could lead to an apparent underestimation of the true uncertainty in ground-motion predictions in the following graphs. For easy comparison, in following figures the maxima of the y-axes are always 25 times the minima.

\subsection{All GMPEs}

Figure 1 presents the predicted PGAs and SA(1 s)s from all programmed GMPEs against publication date for a $M_{w} 6$ strike-slip earthquake recorded at $r_{j b}=20 \mathrm{~km}$ on a site classified as NEHRP class C (Eurocode 8 class B) $\left[V_{s, 30}=490 \mathrm{~m} / \mathrm{s}\right.$, Boore and Atkinson (2008)]. This scenario was considered since it is roughly the best-represented scenario in global strongmotion databases (e.g. Bommer and Scott, 2000) and hence if predictions from GMPEs are becoming more similar then it should be noticeable for such a scenario. A few predicted ground motions are off the graphs shown on Figure 1 often due to extrapolating a model far outside its range of applicability. Figure 1 shows that the dispersion in predicted earthquake ground motions from different GMPEs is large (the ratio between the smallest and largest predictions is greater than ten) and that this scatter is not obviously reducing with time (even when considering only models passing basic quality control criteria). As a measure of this the standard deviation of the common logarithm of median estimates for each five-year interval are computed: for both PGA and $\mathrm{SA}(1 \mathrm{~s})$ these standard deviations are around 0.2. Also roughly constant are the average PGA and SA(1s) over time.

Assuming that predictions from GMPEs from all regions will tend to a single value over time makes the assumption that regional dependence of ground motions (e.g. Douglas, 2007) is minimal. However, this assumption is the focus of strong debate in the literature [e.g. see 
references in Douglas (2007)]. In addition, Figure 1 plots many models that do not pass basic quality assurance criteria concerning peer-review, publication of basic information on the underlying dataset, independent and dependent parameters and extrapolation far outside the range of applicability of the model (e.g. Cotton et al, 2006). These issues complicate the use of Figure 1 when looking for a reduction in epistemic uncertainty. Therefore, it was decided to conduct the analysis for smaller geographical regions for which many models exist: western and eastern North America (WNA and ENA), Europe, the Mediterranean and the Middle East (EMME) and subduction zones; and also to indicate those models that were published in peer-reviewed international journals and give basic details of the datasets used for their derivation [criteria 2 and 3 of Cotton et al (2006)], which act as basic quality control.

[Fig. 1 about here.]

\subsection{Western North America (WNA)}

Epistemic uncertainty in ground-motion prediction is linked to the quality and quantity of available strong-motion data. Therefore, given an abundant data set, predictions for a considered scenario should match the average ground motion observed for that scenario. Hence, in addition to plotting the predictions from various GMPEs, the median ground motion for the considered scenario obtained from a large (over 13000 records from over 2500 events) strong-motion database [the data from the Internet Site for European Strong-motion Data (ISESD) (Ambraseys et al, 2004) with the addition of many accelerograms from WNA and elsewhere (e.g. Chiou et al, 2008)] are shown up to a given date. The median should track the predictions and the variability in the median should also show a reduction. Note that the variability in the median is not the same as the aleatory variability in an individual estimated ground motion [modelled by the standard deviation, $\sigma$ (e.g. Strasser et al, 2009)] since given enough data the median can be well predicted but the variability in an individual estimate will remain high due to the complexity of earthquake ground motion generation and propagation (e.g. Douglas, 2007). The variabilities of the medians are computed here by dividing the standard deviation by $\sqrt{n}$, where $n$ is the number of records used to compute the standard deviation. When constructing the strong-motion database employed here particular attention was given to the collection of data from shallow crustal earthquakes in active tectonic regions. Therefore, medians and variabilities are only plotted on the graphs for WNA and EMME and not on the graphs for ENA (a stable continental region, SCR) 
nor for subduction zones. The medians and their variabilities were computed by considering the available data within $0.5-M_{w}$ units and $10 \mathrm{~km}$ of the scenario of interest and excluding a consideration of local site conditions and style of faulting. It could be argued that these bins are too broad and that a consideration of local site effects should have been made. However, given the limited data available, particularly for $M_{w}>7$, narrow bins would lead to statistics based on few records from only a handful of earthquakes. Tests were made using narrower bins (within $0.25-M_{w}$ units and $5 \mathrm{~km}$ of the scenario of interest) and considering only records from NEHRP C classes and similar results were obtained but based on much smaller sample sizes, particularly before 1990. The median ground motions computed from averaging data within broad bins should not be strongly affected by the width of the bins but the variabilities of these medians may be slightly overestimated.

Figure 2 shows the results of the analysis for WNA for the scenario: $M_{w} 6$ at $r_{j b}=20 \mathrm{~km}$. This figure does not clearly show a decrease in the scatter of predicted ground motions after about 1980 [the narrowing of the limits at that time could be related to the occurrence of the Imperial Valley earthquake in 1979, which significantly increased the amount of nearsource strong-motion data available (e.g. Joyner and Boore, 1981)]. Standard deviations of the median PGAs and SA(1 s)s equal roughly 0.1 (half of the value when considering all equations). The median ground motions and their confidence limits obtained from averaging observations match the predictions from the GMPEs quite well although they are slightly higher. The confidence limits from the observations are narrower than the scatter in the predictions from the GMPEs, which suggests that the variation in predictions from GMPEs could be slightly over-estimating the actual uncertainty in the prediction of the median ground motion for this scenario.

[Fig. 2 about here.]

Figure 3 repeats the exercise for the scenario $M_{w} 7.5$ at $r_{j b}=10 \mathrm{~km}$, for which observational strong-motion databases are still limited. As expected the scatter in predictions for this scenario shows a slight decrease with time, particularly in the past decade when more data to constrain predictions for larger magnitudes became available. In addition, the predictions from the GMPEs show a greater scatter (standard deviation of roughly 0.15) for this scenario than for $M_{w} 6$ at $r_{j b}=20 \mathrm{~km}$ since there are still few records to help modellers constrain their GMPEs in the near-source region of large magnitudes. Large outliers are invariably attributable to extrapolation of models outside their strict range of applicability and 
the use of point-source distance metrics. The median ground motions based on the averaging of observations match the predictions reasonably well although they are below the predictions from the GMPEs. Recent data from large earthquakes (e.g. Chi-Chi, 1999; Kocaeli, 1999; Denali, 2002) have shown lower ground motions than expected (e.g. Ellsworth et al, 2004), which is in line with the observations made here. Like for the previous scenario the confidence limits on the medians from the averaging are narrower than the scatter in the predictions from the GMPEs. This is partly due to multiple records from the same earthquake being used to compute these averages, which could lead to an underestimation of the true variability in the medians.

[Fig. 3 about here.]

It is not just for large earthquakes that there is considerable epistemic uncertainty in ground-motion predictions. Figure 4 shows the results for the scenario $M_{w} 5$ at $r_{j b}=10 \mathrm{~km}$, which shows similar scatter to the scenario $M_{w} 7.5$ at $r_{j b}=10 \mathrm{~km}$. The median ground motions from averaged observations match the predictions from the GMPEs quite well although they are slightly lower.

[Fig. 4 about here.]

\subsection{Europe, the Mediterranean and Middle East (EMME)}

Over the past three decades many dozens of GMPEs have been published for the EMME, either combining data from many countries within this region or using only from a specific country (or part of a country) (e.g. Bommer et al, 2010b), although until recently there were few published models for spectral ordinates. Figures 5, 6 and 7 show the results of the same analysis as was performed for WNA. Compared with the corresponding graphs for WNA the scatter in predictions of the median PGA and SA(1s) are greater (standard deviations roughly 0.15 for $M_{w} 6$ at $20 \mathrm{~km}$ and about 0.25 for $M_{w} 7.5$ at $10 \mathrm{~km}$ and $M_{w} 5$ at $10 \mathrm{~km}$ ) although there is some evidence that predictions for PGA are becoming more consistent (since about 2000) as data coverage improves. The large scatter in predictions for $M_{w} 7.5$ at $r_{j b}=10 \mathrm{~km}$ is evidence of the lack of available data for such a scenario from EMME. This strongly suggests the need to introduce data from other regions (e.g. WNA) into datasets used to derive GMPEs for EMME in order to better constrain predictions near to the source of large earthquakes. As has been recently noted by, for example, Douglas 
(2007) and Bommer et al (2010b) there is no strong evidence for a significant difference in ground motions from moderate and large shallow crustal earthquakes between WNA and EMME and, therefore, it is more defensible to combine datasets from different regions when deriving empirical GMPEs. The large scatter in predictions for the scenario $M_{w} 5$ at $10 \mathrm{~km}$ is surprising since strong-motion databases for EMME are richer at small magnitudes than at large magnitudes. Some of this scatter could be due to a dependence of median ground motions on region for different parts of EMME because data from small earthquakes may display strong regional variations (e.g. through stress drop differences) even when data from larger events does not show such regional dependency (e.g. Atkinson and Morrison, 2009; Chiou et al, 2010).

[Fig. 5 about here.]

[Fig. 6 about here.]

[Fig. 7 about here.]

\subsection{Stable continental regions (SCRs)}

Figures 8 and 9 show the results of a similar analysis for SCRs (mainly ENA). Note that unlike the previous figures, the vast majority of predictions plotted come from simulationbased GMPEs rather than empirical GMPEs due to the lack of strong-motion data from this region. This means that the variation amongst predictions is more under the control of the GMPE developers since they define the parameters and ranges used to develop the simulations that are the basis of these relations. Both these figures show that there has not been much decrease in the variation between predictions from the GMPEs for SCRs over the past 25 years. In addition, the difference between predictions for SCRs is higher than for WNA (standard deviation of the median predictions is roughly 0.2 ). These findings are in line with expectations since there are still only a handful of records from SCRs from earthquakes with $M_{w}>6$ that can be used to constrain predictions (e.g. Atkinson and Boore, 2006). It is surprising that the scatter in PGA predictions for the $M_{w} 7.5-10 \mathrm{~km}$ scenario is not greater than the scatter for the smaller event at greater distances since there are no records from SCRs available for such a scenario. This strongly suggests that the variation in predictions from GMPEs for SCRs is underestimating the true epistemic uncertainty in the prediction of ground motions for large events in such regions. A similar conclusion was 
reached by Atkinson (2007). Note that due to higher average stress drops $(\Delta \sigma)$ in SCR earthquakes and lower path $(Q)$ and site $(\kappa)$ attenuation in stable regions, median highfrequency ground motions (e.g. PGA) are higher than those in active areas (e.g. WNA and EMME) (e.g. Campbell, 2003). This can be seen by comparing Figures 2 and 8 , for example.

[Fig. 8 about here.]

[Fig. 9 about here.]

\subsection{Japan (subduction zones)}

The final geographical region considered here is Japan, which has a long history of strongmotion recording and for which many GMPEs have been derived. In addition to models derived specifically for Japan, models derived for subduction zones in general are also considered since the majority of these are heavily based on Japanese data. Since most strongmotion data from Japan are from subduction events predictions are compared for an interface event with a dip of $15^{\circ}$. Two scenarios are considered: $M_{w} 6.5$ at at rupture distance $\left(r_{\text {rup }}\right)$ of $50 \mathrm{~km}$, which is roughly the centre of the magnitude-distance distribution of subduction data used by Atkinson and Boore (2003) and therefore where predictions should be most similar, and $M_{w} 8$ at $r_{\text {rup }}=20 \mathrm{~km}$, for which little data is available. Again a NEHRP class C site is assumed. As mentioned above the strong-motion databank used for this analysis is not rich in records from subduction-zone earthquakes and, therefore, predictions are not compared to observations in this section.

Figures 10 and 11 show that recent GMPEs for Japan and subduction zones show slightly more consistency than GMPEs from the 1990s or earlier but that there is still considerable scatter in the predictions of the median PGA and SA(1 s) even for a scenario such as $M_{w} 6.5$ at $50 \mathrm{~km}$ for which considerable data exists. The variation in the predictions is higher than those for WNA (standard deviation of the medians is roughly 0.2 for PGA and about 0.1 for $\mathrm{SA}(1 \mathrm{~s})$ for $M_{w} 6.5$ at $\left.50 \mathrm{~km}\right)$. As expected, due to the lack of observations from close to large interface earthquakes there is more variation in the median predictions for $M_{w} 8$ at $20 \mathrm{~km}$ (standard deviations of roughly 0.3 ) than for the other scenario.

[Fig. 10 about here.]

[Fig. 11 about here.] 


\section{Conclusions}

In this article the expected reduction in epistemic uncertainty in earthquake ground-motion prediction thanks to the accumulation of data and knowledge has been indirectly assessed by examining the dispersion in predicted ground motions from published GMPEs. This analysis has shown that although epistemic uncertainty seems to be reducing slightly for moderate events, there is still large uncertainty in the estimation of ground motions even for scenarios that are well represented in strong-motion databanks (e.g. $M_{w} 6$ at $r_{j b}=20 \mathrm{~km}$ for shallow crustal events and $M_{w} 6.5$ at $r_{\text {rup }}=50 \mathrm{~km}$ for interface subduction earthquakes). For WNA the epistemic uncertainty in the median PGA is roughly 25\% (using the standard deviation of 0.1 computed over recent five-year intervals) for moderate earthquakes. For EMME it is higher (roughly $40 \%$ using the computed standard deviation of 0.15 ). For areas with limited datasets, e.g. SCRs, the uncertainty in the median ground motions is higher (factors of three between predictions from different models are not uncommon). In addition, even with the accumulation of large datasets from subduction zones (e.g. in Japan) there is still large variation in predicted ground motions from, even moderate, subduction earthquakes. The results presented in this article clearly demonstrate that even for the best-investigated regions (e.g. WNA) that epistemic uncertainty in ground-motion prediction is real and must be accounted for in seismic hazard assessments through the use of multiple models capturing the range of possible median ground motions and their associated aleatory variabilities. Methods for the selection and adjustment of appropriate GMPEs are discussed by, for example, Cotton et al (2006) and Bommer et al (2010a).

Acknowledgements An early version of this study was submitted to the 9th US and 10th Canadian Conference on Earthquake Engineering (Douglas, 2010). I thank: Landsvirkjun and the University of Iceland for funding my one-year visiting professorship at the Earthquake Engineering Research Centre, Julian Bommer for his detailed comments on an early version of the conference paper and an anonymous reviewer for their useful suggestions for improvements to this journal version.

\section{References}

Ambraseys NN, Smit P, Douglas J, Margaris B, Sigbjörnsson R, Ólafsson S, Suhadolc P,

Costa G (2004) Internet site for European strong-motion data. Bollettino di Geofisica

Teorica ed Applicata 45(3):113-129 
Atkinson GM (2007) Ground motion myths and mysteries. 2007 Joyner Lecture, EERI meeting (Feb. 2007) and SSA meeting (Apr. 2007)

Atkinson GM (2008) Ground-motion prediction equations for eastern North America from a referenced empirical approach: Implications for epistemic uncertainty. Bulletin of the Seismological Society of America 98(3):1304-1318, DOI 10.1785/0120070199

Atkinson GM, Boore DM (2003) Empirical ground-motion relations for subduction zone earthquakes and their application to Cascadia and other regions. Bulletin of the Seismological Society of America 93(4):1703-1729

Atkinson GM, Boore DM (2006) Earthquake ground-motion prediction equations for eastern North America. Bulletin of the Seismological Society of America 96(6):2181-2205, DOI $10.1785 / 0120050245$

Atkinson GM, Morrison M (2009) Observations on regional variability in ground-motion amplitudes for small-to-moderate earthquakes in North America. Bulletin of the Seismological Society of America 99(4):2393-2409, DOI 10.1785/0120080223

Beyer K, Bommer JJ (2006) Relationships between median values and between aleatory variabilities for different definitions of the horizontal component of motion. Bulletin of the Seismological Society of America 96(4A):1512-1522, DOI 10.1785/0120050210

Bommer JJ, Scherbaum F (2008) The use and misuse of logic trees in probabilistic seismic hazard analysis. Earthquake Spectra 24(4):997-1009

Bommer JJ, Scott SG (2000) The feasibility of using real accelerograms for seismic design. In: Elnashai AS, Antoniou S (eds) Implications of Recent Earthquakes on Seismic Risk, Imperial College Press, pp 115-126

Bommer JJ, Scherbaum F, Bungum H, Cotton F, Sabetta F, Abrahamson NA (2005) On the use of logic trees for ground-motion prediction equations in seismic-hazard analysis. Bulletin of the Seismological Society of America 95(2):377-389, DOI 10.1785/0120040073

Bommer JJ, Douglas J, Scherbaum F, Cotton F, Bungum H, Fäh D (2010a) On the selection of ground-motion prediction equations for seismic hazard analysis. Seismological Research Letters Submitted

Bommer JJ, Stafford PJ, Akkar S (2010b) Current empirical ground-motion prediction equations for Europe and their application to Eurocode 8. Bulletin of Earthquake Engineering 8(1):5-26, DOI 10.1007/s10518-009-9122-9

Boore DM, Atkinson GM (2008) Ground-motion prediction equations for the average horizontal component of PGA, PGV, and 5\%-damped PSA at spectral periods between $0.01 \mathrm{~s}$ 
and 10.0s. Earthquake Spectra 24(1):99-138, DOI 10.1193/1.2830434

Campbell KW (2003) Prediction of strong ground motion using the hybrid empirical method and its use in the development of ground-motion (attenuation) relations in eastern North America. Bulletin of the Seismological Society of America 93(3):1012-1033

Campbell KW, Bozorgnia Y (2007) Campbell-Bozorgnia NGA ground motion relations for the geometric mean horizontal component of peak and spectral ground motion parameters. PEER Report 2007/02, Pacific Earthquake Engineering Research Center, College of Engineering, University of California, Berkeley

Chiou B, Darragh R, Gregor N, Silva W (2008) NGA project strong-motion database. Earthquake Spectra 24(1):23-44, DOI 10.1193/1.2894831

Chiou B, Youngs R, Abrahamson N, Addo K (2010) Ground-motion attenuation model for small-to-moderate shallow crustal earthquakes in California and its implications on regionalization of ground-motion prediction models. Earthquake Spectra In press

Chiou BSJ, Youngs RR (2008) NGA model for average horizontal component of peak ground motion and response spectra. PEER Report 2008/09, Pacific Engineering Research Center, College of Engineering, University of California, Berkeley

Cotton F, Scherbaum F, Bommer JJ, Bungum H (2006) Criteria for selecting and adjusting ground-motion models for specific target regions: Application to central Europe and rock sites. Journal of Seismology 10(2):137-156, DOI 10.1007/s10950-005-9006-7

Douglas J (2003) Earthquake ground motion estimation using strong-motion records: A review of equations for the estimation of peak ground acceleration and response spectral ordinates. Earth-Science Reviews 61(1-2):43-104

Douglas J (2004) Ground motion estimation equations 1964-2003: Reissue of ESEE Report No. 01-1: 'A comprehensive worldwide summary of strong-motion attenuation relationships for peak ground acceleration and spectral ordinates (1969 to 2000)' with corrections and additions. Tech. Rep. 04-001-SM, Department of Civil and Environmental Engineering; Imperial College of Science, Technology and Medicine; London; U.K., URL http://www3.imperial.ac.uk/civilengineering/research/researchnewsandreports/researchreports

Douglas J (2006) Errata of and additions to 'Ground motion estimation equations 1964-2003'. Intermediary report RP-54603-FR, BRGM, Orléans, France, URL http://www.brgm.fr/publication/rechRapportSP.jsp

Douglas J (2007) On the regional dependence of earthquake response spectra. ISET Journal of Earthquake Technology 44(1):71-99 
Douglas J (2008) Further errata of and additions to 'Ground motion estimation equations 1964-2003'. Final report RP-56187-FR, BRGM, Orléans, France, URL http://www.brgm.fr/publication/rechRapportSP.jsp

Douglas J (2010) Assessing the epistemic uncertainty of ground-motion predictions. In: Proceedings of the Ninth U.S. National and 10th Canadian Conference on Earthquake Engineering: Reaching Beyond Borders

Ellsworth WL, Celebi M, Evans JR, Jensen EG, Kayen R, Metz MC, Nyman DJ, Roddick JW, Spudich P, Stephens CD (2004) Near-field ground motion of the 2002 Denali Fault, Alaska, earthquake recorded at Pump Station 10. Earthquake Spectra 20(3):597615 , DOI $10.1193 / 1.1778172$

Gutenberg B, Richter CF (1956) Earthquake magnitude, intensity, energy, and acceleration (second paper). Bulletin of the Seismological Society of America 46(1):105-145

Joyner WB, Boore DM (1981) Peak horizontal acceleration and velocity from strong-motion records including records from the 1979 Imperial Valley, California, earthquake. Bulletin of the Seismological Society of America 71(6):2011-2038

Strasser FO, Abrahamson NA, Bommer JJ (2009) Sigma: Issues, insights, and challenges. Seismological Research Letters 80(1):40-56, DOI 10.1785/gssrl.80.1.40 


\section{List of Figures}

1 Predicted PGA and SA(1s) (unfilled black circles) for a $M_{w} 6$ strike-slip earthquake at $r_{j b}=20 \mathrm{~km}$ on a NEHRP C site against publication date for over 250 models published in the literature. Filled red circles indicate models published in peer-reviewed journals and for which basic information on the used dataset is available. Also shown are the median PGA and SA(1 s) within five-year intervals (black line) and the median \pm 1 standard deviation (dashed black lines) based on averaging predictions. . . . . . . . . . . . . .

2 Like Figure 1 but only for WNA models. Also indicated are the median ground motions (solid blue line) and their 16th and 84th confidence limits (dashed blue line) based on averaging records up until that date (see text for details). Up until the end of 2005, 253 records from 56 earthquakes were used to compute these averages. . . . . . . . . . . . . . . 16

$3 \quad$ Like Figure 2 but for $M_{w} 7.5$ at $r_{j b}=10 \mathrm{~km}$. Up until the end of 2003, 129 records from 15 earthquakes were used to compute these averages. . . . . .

4 Like Figure 2 but for $M_{w} 5$ at $r_{j b}=10 \mathrm{~km}$. Up until the end of 1998, 51 records from 30 earthquakes were used to compute these averages. . . . . . 18

5 Like Figure 2 but only for EMME models. . . . . . . . . . . . . . . . . . 19

6 Like Figure 3 but only for EMME models. . . . . . . . . . . . . . . . . . 20

$7 \quad$ Like Figure 7 but only for EMME models. . . . . . . . . . . . . . . . . . 21

8 Like Figure 1 but only for SCR models and for very hard rock $\left(V_{s, 30}=\right.$

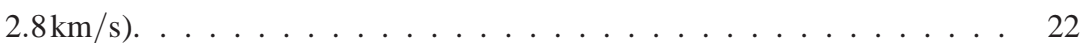

$9 \quad$ Like Figure 8 but for $M_{w} 7.5$ at $r_{j b}=10 \mathrm{~km} \ldots \ldots \ldots 23$

10 Like Figure 1 but for an $M_{w} 6.5$ interface event at $r_{r u p}=50 \mathrm{~km}$ and only for Japanese or subduction-zone GMPEs. . . . . . . . . . . . . . . . . . 24

11 Like Figure 10 but for an $M_{w} 8$ interface event at $r_{r u p}=20 \mathrm{~km} . \ldots \ldots 25$ 

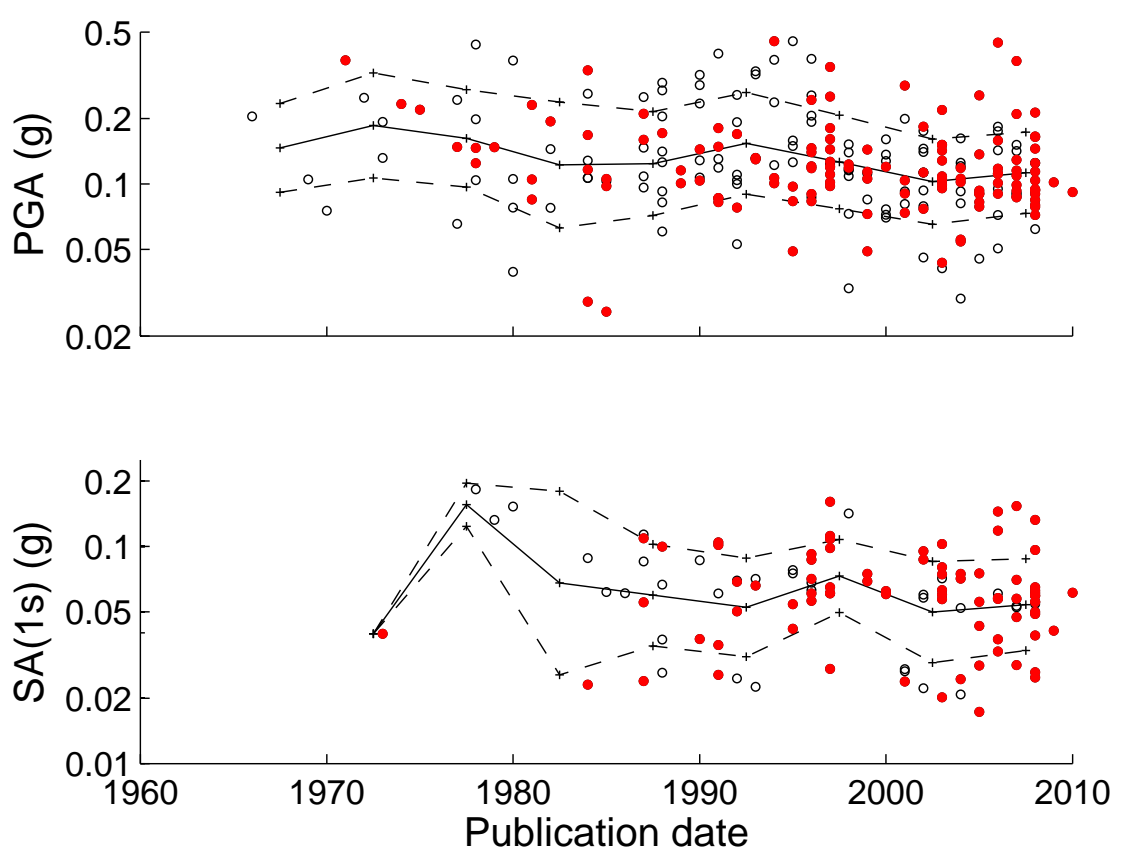

Fig. 1 Predicted PGA and SA(1 s) (unfilled black circles) for a $M_{w} 6$ strike-slip earthquake at $r_{j b}=20 \mathrm{~km}$ on a NEHRP C site against publication date for over 250 models published in the literature. Filled red circles indicate models published in peer-reviewed journals and for which basic information on the used dataset is available. Also shown are the median PGA and SA(1 s) within five-year intervals (black line) and the median \pm 1 standard deviation (dashed black lines) based on averaging predictions. 

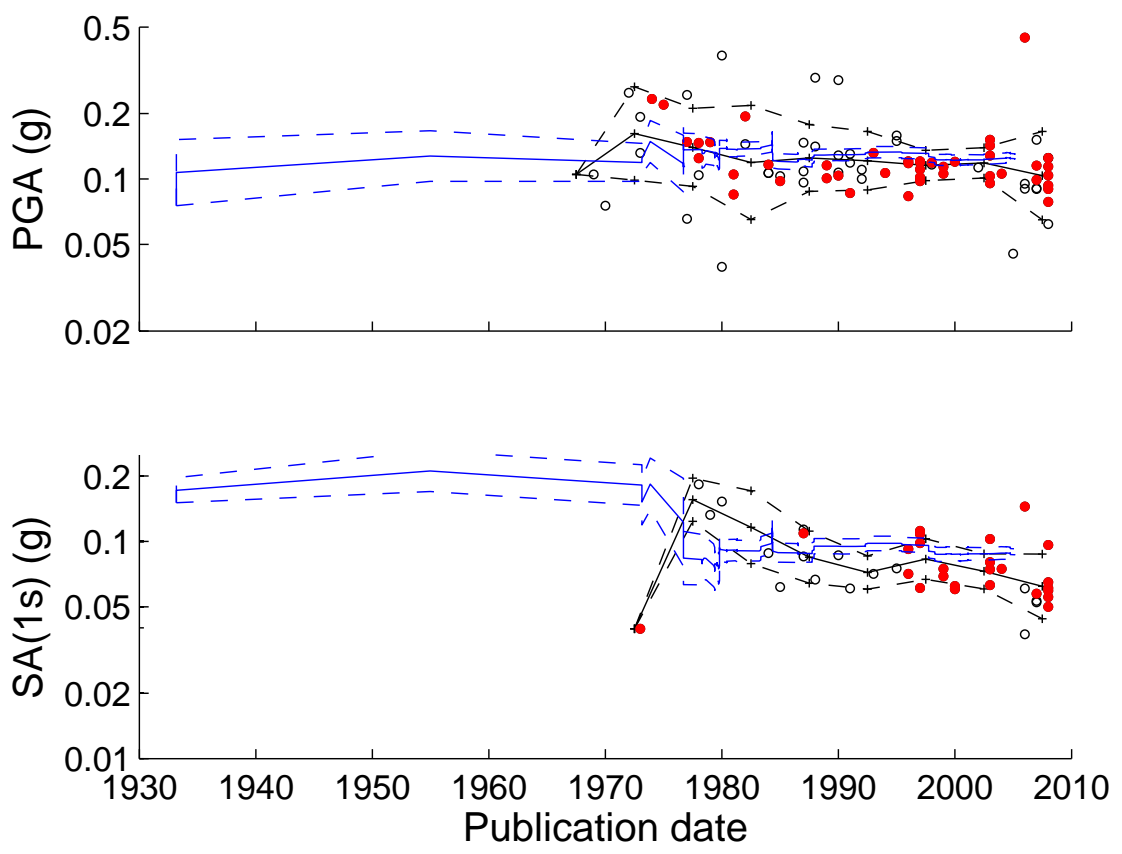

Fig. 2 Like Figure 1 but only for WNA models. Also indicated are the median ground motions (solid blue line) and their 16th and 84th confidence limits (dashed blue line) based on averaging records up until that date (see text for details). Up until the end of 2005, 253 records from 56 earthquakes were used to compute these averages. 

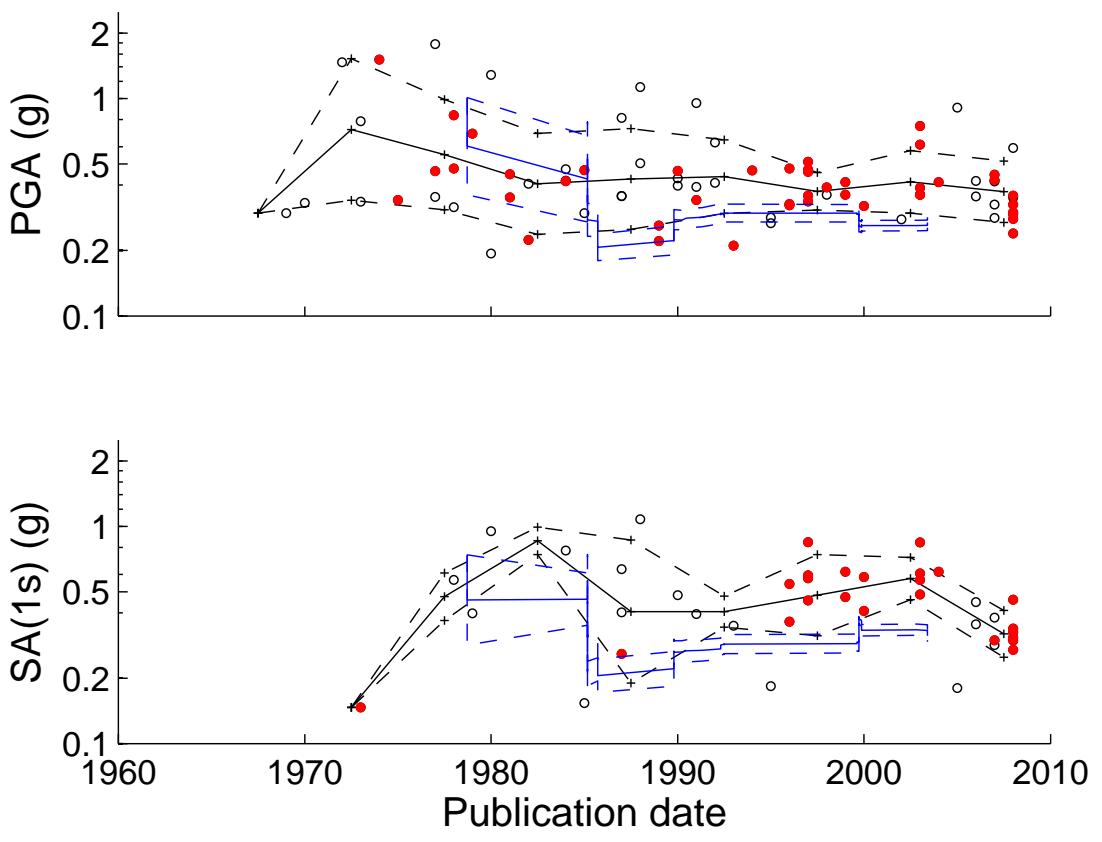

Fig. 3 Like Figure 2 but for $M_{w} 7.5$ at $r_{j b}=10 \mathrm{~km}$. Up until the end of 2003, 129 records from 15 earthquakes were used to compute these averages. 

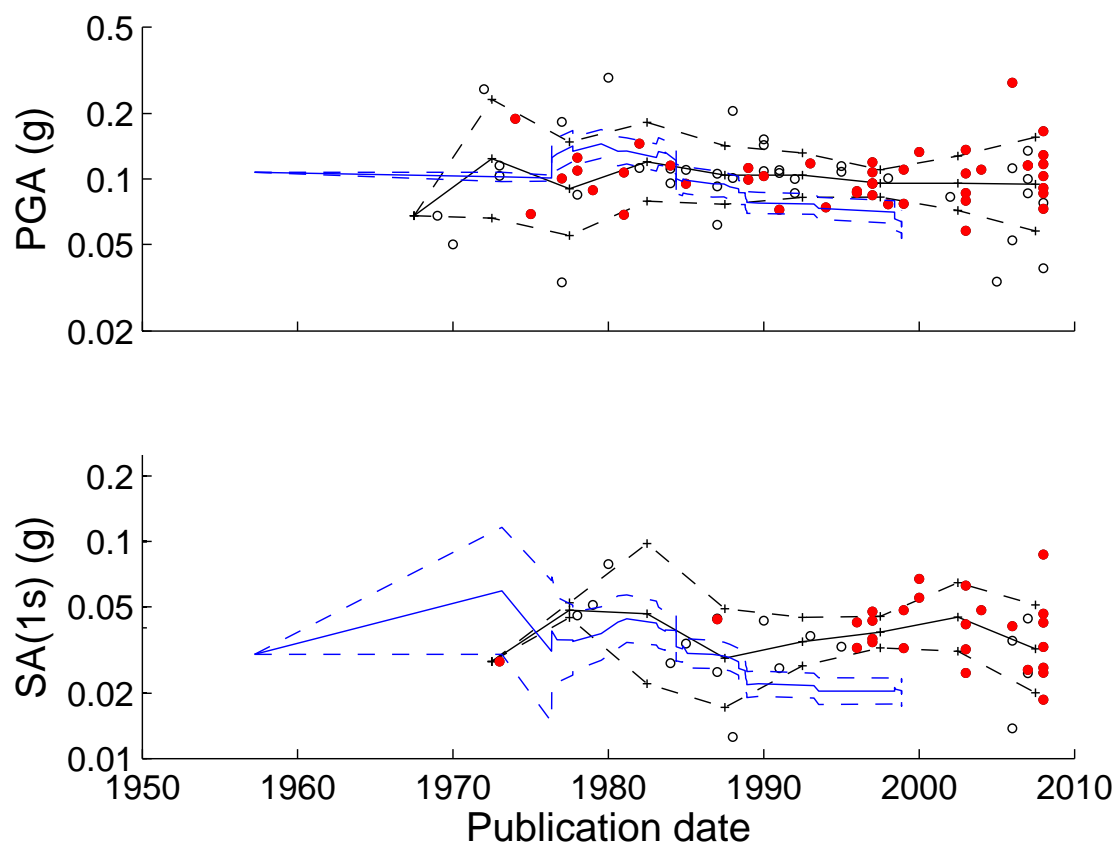

Fig. 4 Like Figure 2 but for $M_{w} 5$ at $r_{j b}=10 \mathrm{~km}$. Up until the end of 1998, 51 records from 30 earthquakes were used to compute these averages. 

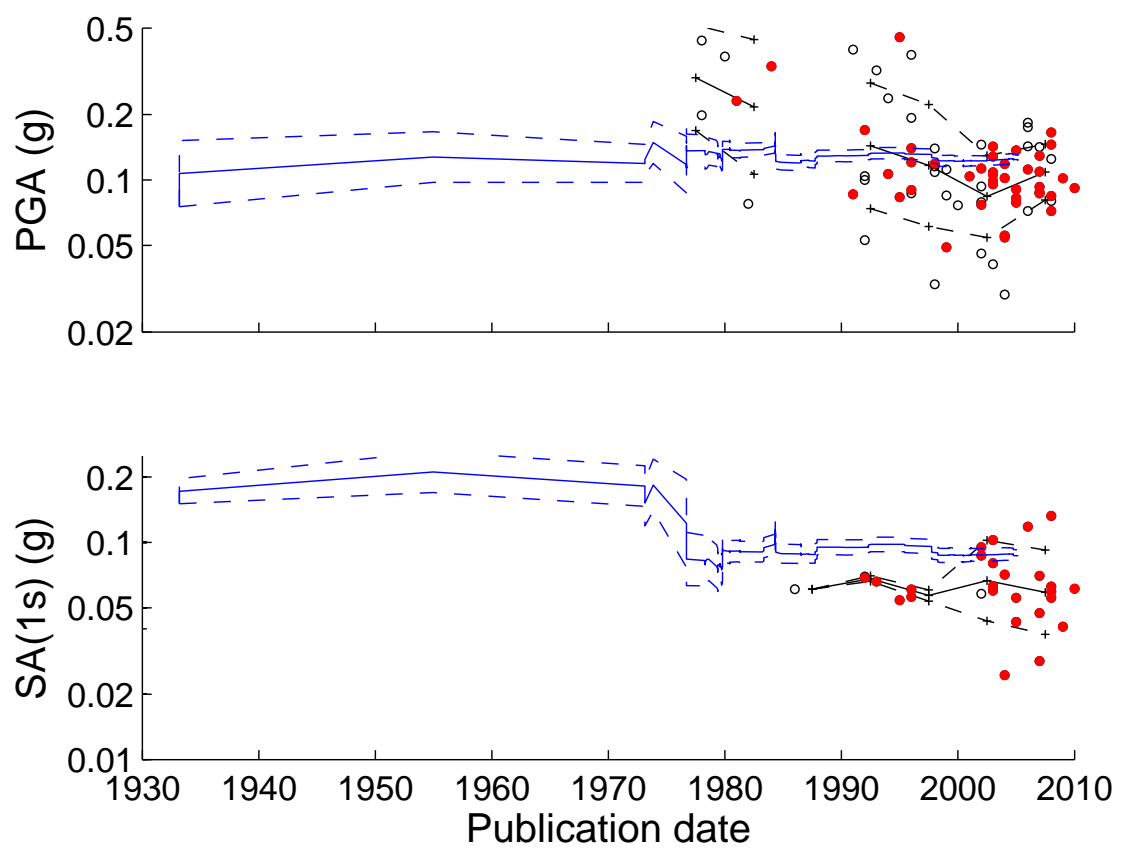

Fig. 5 Like Figure 2 but only for EMME models. 

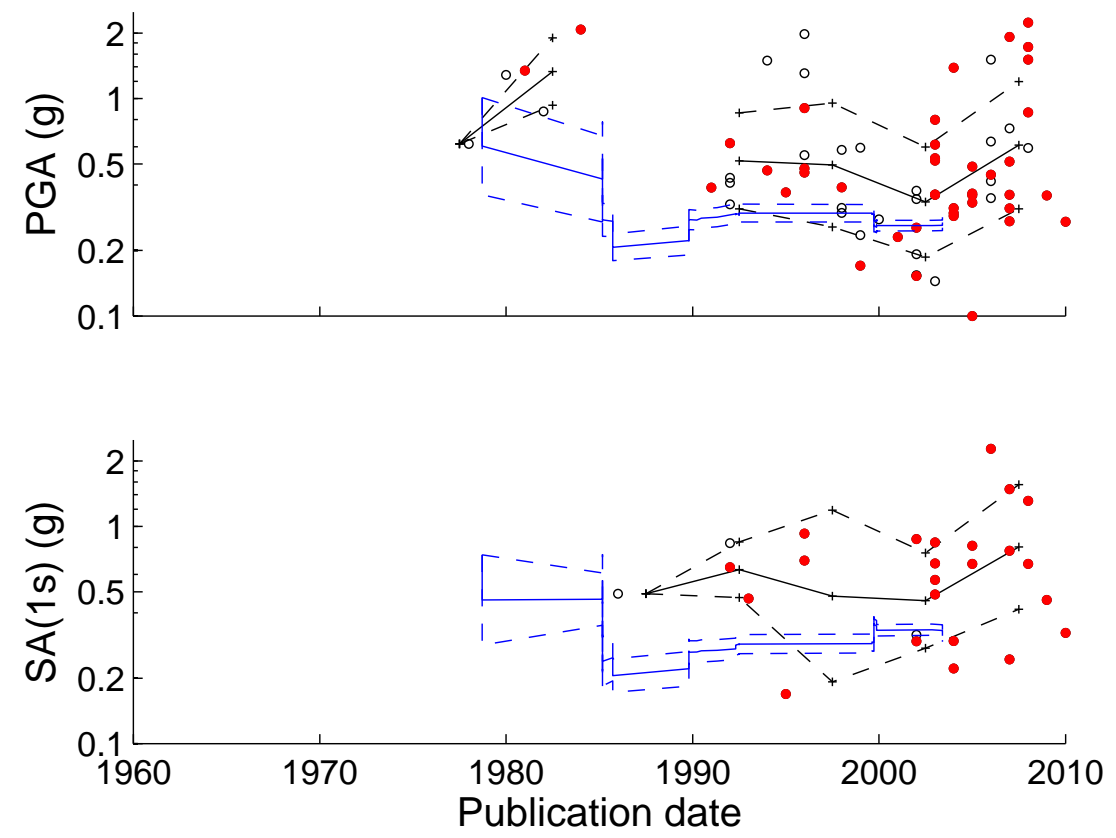

Fig. 6 Like Figure 3 but only for EMME models. 

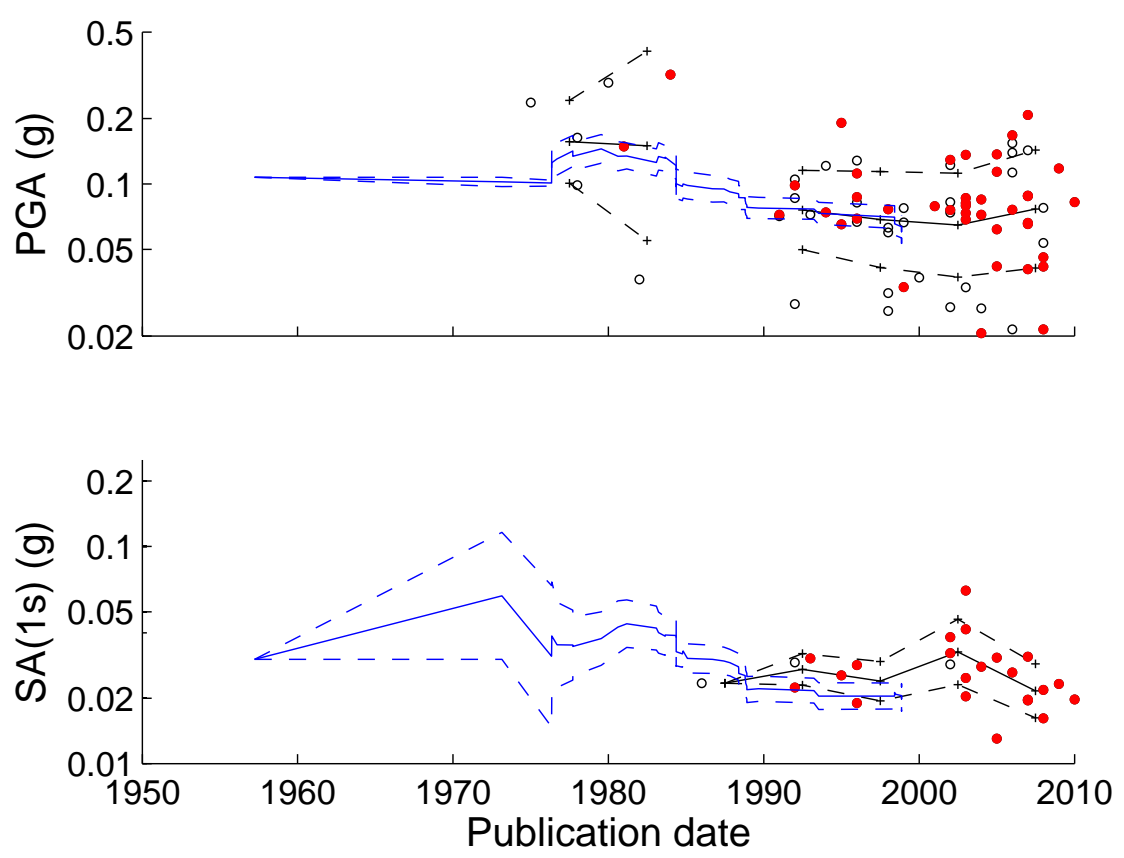

Fig. 7 Like Figure 7 but only for EMME models. 

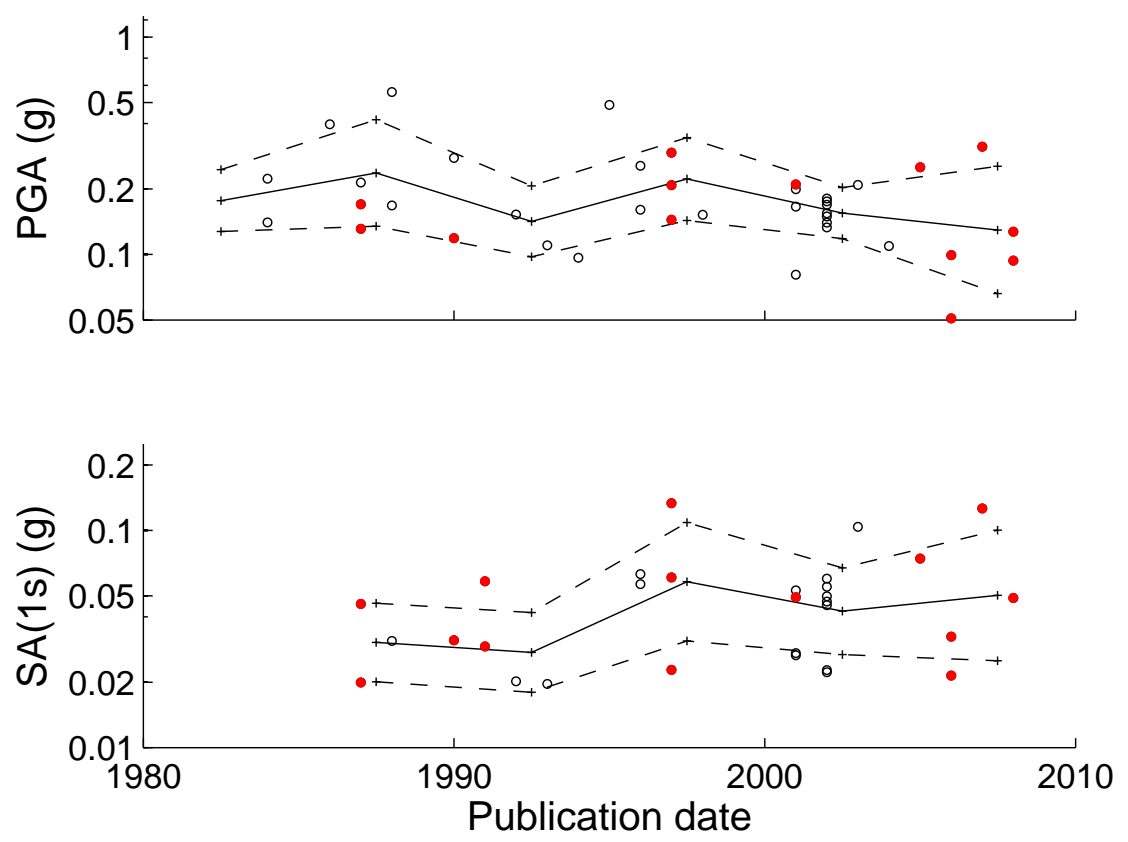

Fig. 8 Like Figure 1 but only for SCR models and for very hard rock $\left(V_{s, 30}=2.8 \mathrm{~km} / \mathrm{s}\right)$. 

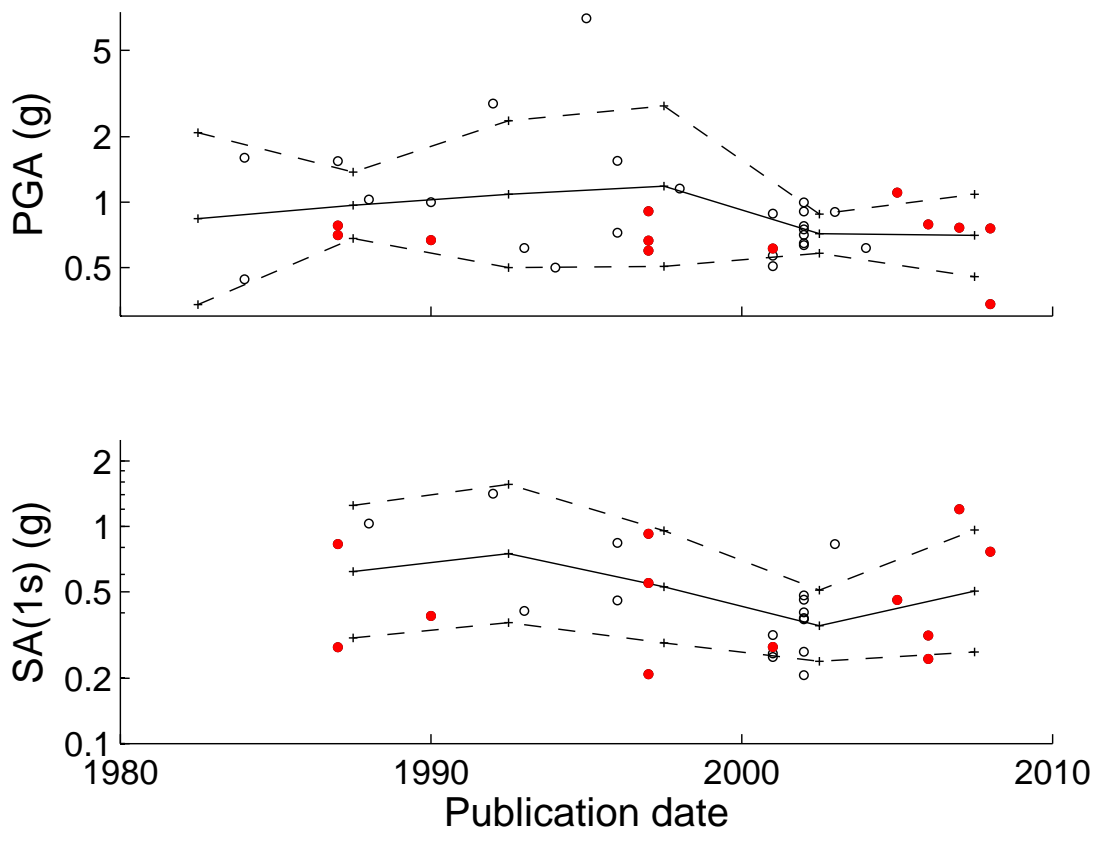

Fig. 9 Like Figure 8 but for $M_{w} 7.5$ at $r_{j b}=10 \mathrm{~km}$. 

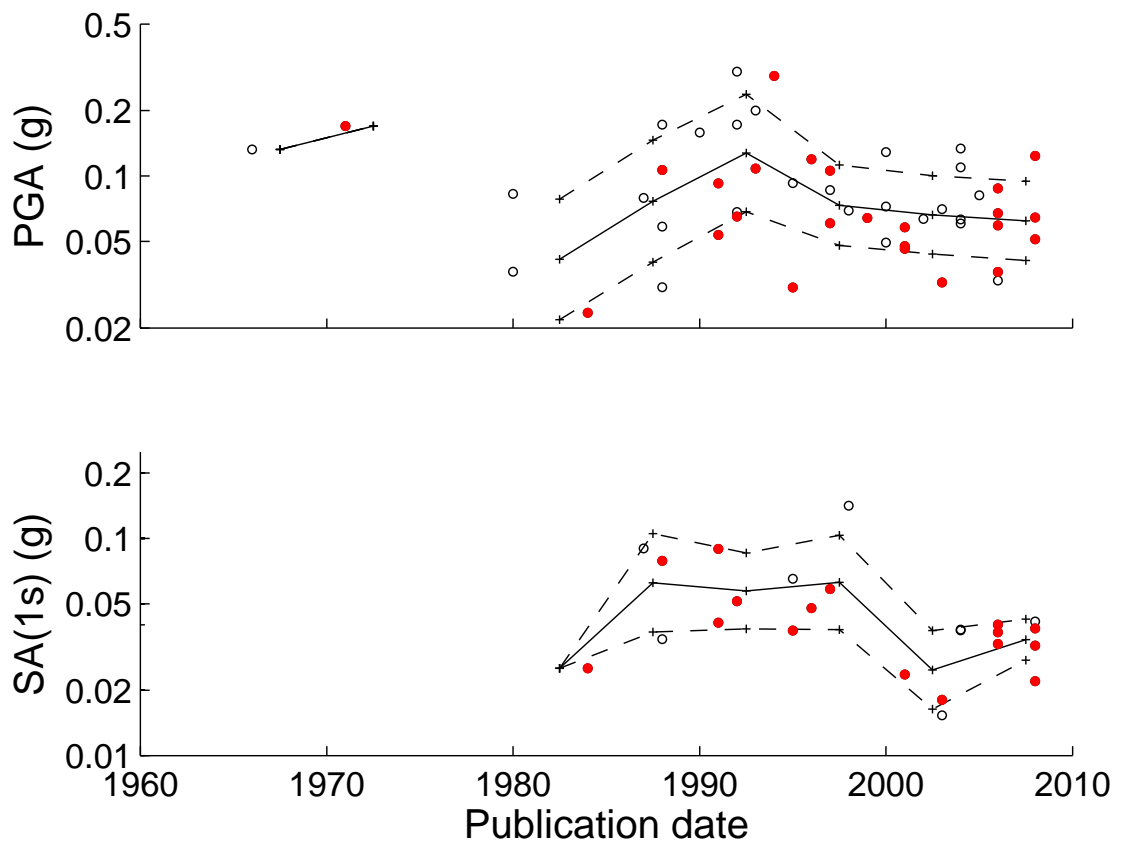

Fig. 10 Like Figure 1 but for an $M_{w} 6.5$ interface event at $r_{r u p}=50 \mathrm{~km}$ and only for Japanese or subductionzone GMPEs. 

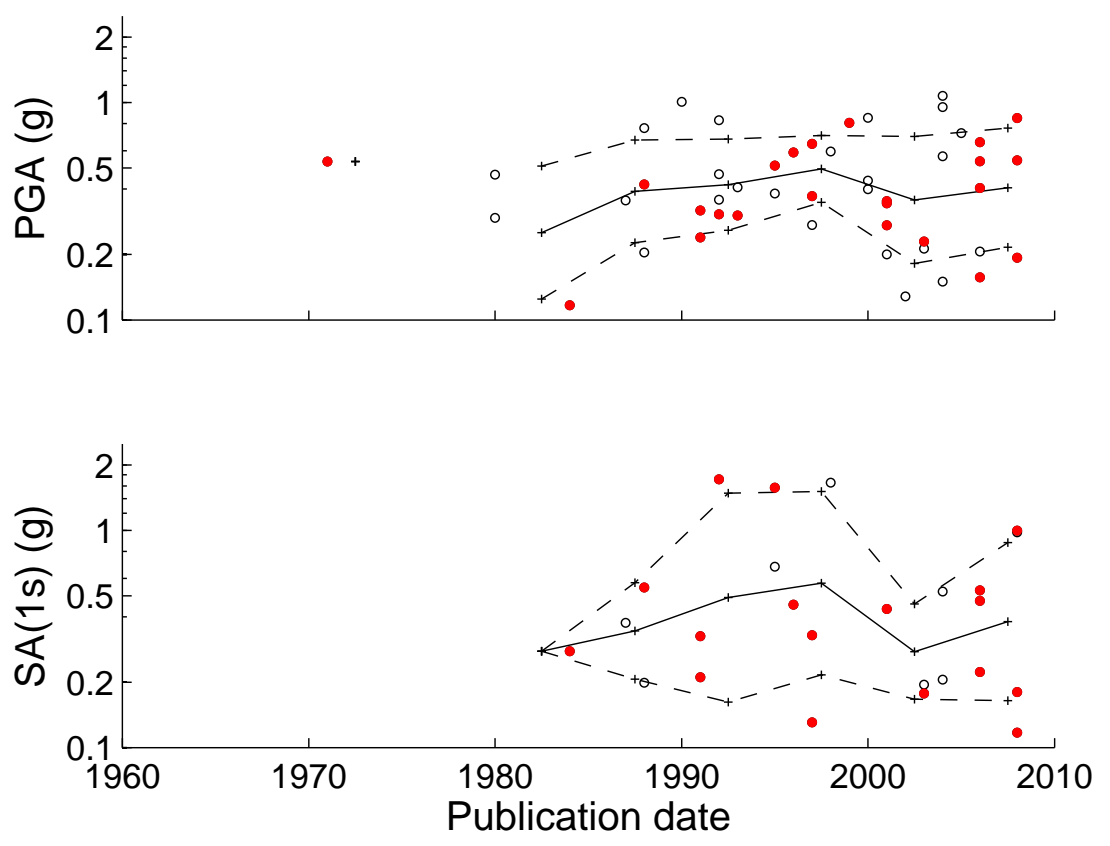

Fig. 11 Like Figure 10 but for an $M_{w} 8$ interface event at $r_{r u p}=20 \mathrm{~km}$. 